\title{
BMJ Open Quality of life among adult patients living with diabetes in Rwanda: a cross- sectional study in outpatient clinics
}

\author{
Charilaos Lygidakis (D) ,,2 Jean Paul Uwizihiwe, ${ }^{2,3}$ Michela Bia, ${ }^{4}$ \\ Francois Uwinkindi, ${ }^{5}$ Per Kallestrup, ${ }^{3}$ Claus Vögele ${ }^{1}$
}

To cite: Lygidakis C, Uwizihiwe JP, Bia M, et al. Quality of life among adult patients living with diabetes in Rwanda: a cross-sectional study in outpatient clinics. BMJ Open 2021;11:e043997. doi:10.1136/ bmjopen-2020-043997

- Prepublication history for this paper is available online. To view these files, please visit the journal online (http://dx.doi org/10.1136/bmjopen-2020043997).

Received 20 August 2020 Revised 21 December 2020 Accepted 03 February 2021

Check for updates

(C) Author(s) (or their employer(s)) 2021. Re-use permitted under CC BY-NC. No commercial re-use. See rights and permissions. Published by BMJ.

${ }^{1}$ Department of Behavioural and Cognitive Sciences, University of Luxembourg, Esch-sur-Alzette, Luxembourg

${ }^{2}$ College of Medicine and Health Sciences, University of Rwanda, Butare, Rwanda

${ }^{3}$ Centre for Global Health, Department of Public Health, Aarhus University, Aarhus, Denmark

${ }^{4}$ Luxembourg Institute of SocioEconomic Research (LISER),

Esch-sur-Alzette, Luxembourg

${ }^{5}$ Division of Non Communicable Diseases, Rwanda Biomedical Center (RBC), Kigali, Rwanda

Correspondence to Dr Charilaos Lygidakis; lygidakis@gmail.com

\section{ABSTRACT}

Objectives To report on the disease-related quality of life of patients living with diabetes mellitus in Rwanda and identify its predictors.

Design Cross-sectional study, part of the baseline assessment of a cluster-randomised controlled trial. Setting Outpatient clinics for non-communicable diseases of nine hospitals across Rwanda.

Participants Between January and August 2019, 206 patients were recruited as part of the clinical trial. Eligible participants were those aged 21-80 years and with a diagnosis of diabetes mellitus for at least 6 months. Illiterate patients, those with severe hearing or visual impairments, those with severe mental health conditions, terminally ill, and those pregnant or in the postpartum period were excluded

Primary and secondary outcome measures Diseasespecific quality of life was measured with the Kinyarwanda version of the Diabetes-39 (D-39) questionnaire. A glycated haemoglobin $(\mathrm{HbA1C})$ test was performed on all patients. Sociodemographic and clinical data were collected, including medical history, disease-related complications and comorbidities.

Results The worst affected dimensions of the D-39 were 'anxiety and worry' (mean=51.63, SD=25.51), 'sexual functioning' (mean=44.58, SD=37.02), and 'energy and mobility' (mean=42.71, SD=20.69). Duration of the disease and $\mathrm{HbA1C}$ values were not correlated with any of the D-39 dimensions. A moderating effect was identified between use of insulin and achieving a target $\mathrm{HbA} 1 \mathrm{c}$ of $7 \%$ in the 'diabetes control' scale. The most frequent comorbidity was hypertension ( $49.0 \%$ of participants), which had a greater negative effect on the 'diabetes control' and 'social burden' scales in women. Higher education was a predictor of less impact on the 'social burden' and 'energy and mobility' scales.

Conclusions Several variables were identified as predictors for the five dimensions of quality of life that were studied, providing opportunities for tailored preventive programmes. Further prospective studies are needed to determine causal relationships.

Trial registration number NCT03376607.

\section{INTRODUCTION}

Sub-Saharan African countries present an ageadjusted diabetes prevalence of $3.9 \%$, that is, the lowest in the world. ${ }^{1}$ Yet, it is estimated

\section{Strengths and limitations of this study}

This is the very first study to report on quality of life in patients living with diabetes in Rwanda.

- The study is also reporting on glycaemic control in these patients, adding relevant knowledge to the limited existing body of literature.

- Despite the relatively small sample size, the study includes patients from seven hospitals offering insight into the territory.

- The study included patients with both types of diabetes since any distinction should be considered with caution.

- Efforts were made to collect reliable data on diabetes-related complications and comorbidities; however, challenges were encountered in obtaining accurate diagnoses.

that these countries bear the highest rates of undiagnosed cases (regional average 59.7\%), and by 2030, prevalence is projected to rise by $48 \%{ }^{1}$ In addition, diabetes-related complications are more frequent in the region. ${ }^{2}$ In Rwanda, the age-adjusted comparative diabetes prevalence was estimated at $5.1 \%$ (after standardisation to the prevalence of the global age distribution). ${ }^{1}$

Diabetes and its complications can cause premature mortality and disability, and exert a dramatic financial impact on both systems and individuals. ${ }^{13}$ The views and perceptions of patients are often neglected when relying solely on physiological measures. Psychological and social factors are also strong indicators of mortality and morbidity. ${ }^{45}$ Quality of life can be employed as an outcome measure providing such additional aspects. ${ }^{6}$ It is a multifaceted concept; it refers to the perception of the individual's life (including those related to physical, psychological and social domains), which can be contextually and temporally affected. ${ }^{7}$ With the increasing life expectancy and prevalence of non-communicable 
diseases, care provision is shifting emphasis towards improving quality of life. ${ }^{8}$

There is a large body of evidence showing how quality of life is affected by diabetes, and its considerable burden of self-care, disease management and behaviour modification, as well as by acute and chronic complications and the presence of chronic medical conditions. ${ }^{5}$ 9-12 The detrimental relationship between comorbidity and the quality of life of patients living with diabetes has been explored and can be classified as additive, synergistic or subtractive. ${ }^{12}{ }^{13}$ Wee $e t ~ a l,{ }^{13}$ for example, noted the additive impact of coexisting hypertension and the subtractive effect of heart disease, hypothesising response shift among the plausible causal mechanisms of such a variation.

Early detection, secondary prevention, care coordination and person-centred approaches can enhance quality of life and mitigate complications, such as impaired vision, macrovascular complications, neuropathy, amputations and depression. ${ }^{14}{ }^{15}$ Contextual differences, including sociodemographic, cultural and epidemiological characteristics of the populations, can influence the perceived quality of life and should be taken into account. ${ }^{16}$ Measuring quality of life and identifying its predictors can provide insight into the needs of patients, contribute to establishing evidence-based targeted preventive programmes and help with service planning. For example, the correlation of educational level with anxiety can be linked to ineffective coping mechanisms. ${ }^{17}$ Policymakers and clinicians can use such information to develop educational and supportive programmes, tailoring interventions to specific groups (eg, patients with complications or comorbidities, caregivers). ${ }^{16} 18$

Research on quality of life in Rwanda has largely focused on people living with HIV/AIDS, due to the prevalence of the infection, and improved access to and availability of antiretroviral therapy, which contribute to higher life expectancy. ${ }^{19-22}$ Conversely, there is very little evidence on quality of life in adult patients living with diabetes in sub-Saharan Africa, while, to the best of our knowledge, no studies have been carried out in Rwanda. The objective of this study was to report on the disease-related quality of life of patients living with diabetes mellitus in a non-representative sample from across the country and to identify potential predictors.

\section{MATERIALS AND METHODS \\ Sample and setting}

Data for the current cross-sectional study are part of the baseline assessment of patients recruited for the $\mathrm{D}^{2} \mathrm{R}$ wanda cluster-randomised controlled trial between January and August 2019 (clinical trial registration: NCT03376607). The protocol of the D²Rwanda Study, which aims at determining the efficacy of an integrated mobile-health and community-health-worker programme for the management of diabetes in primary healthcare in Rwanda, has been described elsewhere. ${ }^{23}$ During the first
8 months of 2019, patients were recruited in outpatient clinics for non-communicable diseases in seven out of nine hospitals of the trial: Bushenge, Kibungo, Kibuye, Kinihira, Muhima, Ruhengeri and Rwamagana. Eligible participants were those aged $21-80$ years and with a diagnosis of diabetes mellitus for at least 6 months. Illiterate patients, those with severe hearing or visual impairments, those with severe mental health conditions, terminally ill, and those pregnant or in the postpartum period were excluded. Written informed consent was obtained from all participants before any of the study procedures took place.

\section{Measurements}

Sociodemographic and clinical data were collected (including medical history, disease-related complications and comorbidities) by the clinic nurses. The individual's type of diabetes was retrieved from the available patient records. An ad-hoc glycated haemoglobin (HbAlc) test was performed for all patients to assess their glycaemic control. HbAlc was selected over measuring fasting blood glucose because it is more informative of the patient's glycaemic control between follow-ups, remains unaffected by attempts to adhere better in the days leading up to the appointment with the care provider and is unaffected by the inability to fast appropriately in the 8 hours before the examination. ${ }^{2}$ Rwanda's guidelines for the management of non-communicable diseases define $\mathrm{HbAlc}$ values of $8 \%$ or below as indicative of good glycaemic control. ${ }^{24} \mathrm{In}$ our analysis, we also considered a stricter target of $7 \% .{ }^{25}$ The patients' medications were also recorded and, for this analysis, insulin was not distinguished according to type, regimen or units injected.

For the evaluation of quality of life, the Diabetes-39 (D-39) questionnaire was employed. ${ }^{26}$ This diseasespecific, widely used instrument has been recommended for a broad spectrum of patient populations and has yielded acceptable reliability. ${ }^{27}$ It consists of 39 items, capturing broad aspects of quality of life in five domains: diabetes control (12 items), anxiety and worry (4 items), social burden ( 5 items), sexual functioning ( 3 items), and energy and mobility ( 15 items). Respondents evaluate the extent to which their quality of life has been affected by different aspects related to diabetes during the preceding 4 weeks. Each item can be marked on a 7-point Likert scale, presented as consecutively numbered boxes ranging from 'not affected at all' to 'extremely affected'.

Patients completed the Kinyarwanda version of the questionnaire in the premises of the clinics. The translation and cross-cultural adaptation were conducted by the same research group following a standard protocol. ${ }^{28}$ The preliminary psychometric evaluation of the Kinyarwanda version of the questionnaire based on 309 patients with diabetes yielded good composite reliability and a satisfactory approximate model fit of the five-factor model. The full results of this process will be reported in a publication elsewhere. To our knowledge, no other disease-specific 
quality-of-life questionnaire has been validated into Kinyarwanda up to now.

Instructions of the original instrument suggest that each item should be scored with 0.5 step depending on where the respondent places the cross (eg, if the participant places a cross on the left-side margin of the first box, that should be interpreted as 0.5 ). Thus, the possible score for each item would be between 0.5 and 7.5. Nevertheless, during the cultural adaptation of the questionnaire, it was observed that participants had difficulties with marking different parts of the space of the boxes according to the answer they wanted to give. Therefore, a simplified version was proposed, and only the single boxes were considered (ie, each item could be scored from 1 to 7 , with a step of 1), similarly to the method suggested in the Brazilian adaptation of the questionnaire. ${ }^{29}$ Finally, each of the five dimensions was summed up, and the resulting raw scores were transformed into scales ranging from 0 to 100 using a linear transformation: (raw score-minimum value)/ (maximum value - minimum value) $\times 100$. According to the D-39 scoring, questionnaires with more than four missing items would be omitted from the analysis; no summative scores would be calculated in case of a certain number of missing items (diabetes control: $>3$ items; anxiety and worry: >1 item; social burden: $>1$ item; sexual functioning: $>0$ item; energy and mobility: $>3$ items). In other cases, missing values would be replaced by the mean score of the patient for that dimension.

The questionnaire also includes two supplementary 'overall ratings', in which respondents use the same seven-box Likert scale to evaluate their perceived overall quality of life (ranging from 'lowest quality' to 'highest quality') and the severity of their diabetes (ranging from 'not severe at all' to 'extremely severe').

\section{Statistical analysis}

Statistical analyses were performed on Stata V.16. Data were initially explored with descriptive statistics. For the D-39, observations with more than four missing items (except for the three 'sexual functioning' items) were excluded from the analysis. We first investigated associations with the five domains of the D-39 across sociodemographic and clinical groups. Differences between two, and three or more groups were assessed with the Mann-Whitney $\mathrm{U}$ and the Kruskal-Wallis tests, respectively. This non-parametric approach was chosen as the summated ratings derive from ranked variables. ${ }^{30}$ For the Mann-Whitney U test, effect sizes were estimated based on $z$ values and were considered as small, medium and large for $r$ values of $0.10,0.30$ and 0.50 , respectively. ${ }^{31}$ In post-hoc tests for planned contrasts, the Bonferroni correction was applied. Correlations between continuous variables were assessed with Spearman's rank correlation coefficient; values below 0.40 were interpreted as weak, those between 0.40 and 0.69 as moderate, and those 0.70 and above as strong. ${ }^{32} 33$

Multiple linear regression analyses were conducted for the five domains of the D-39 questionnaire. Those sociodemographic and clinical variables which were found significant in the correlations or comparisons of differences, as well as those conceptually similar, were used to determine the predictors of the models. Continuous variables were centred to facilitate the interpretation of interaction terms. Interactions were evaluated for those variables with a probable combination effect. For each of the D-39 dimensions, a series of models was produced, and after assessing residuals and model fit, the most appropriate candidates were selected.

\section{Patient and public involvement}

Patients or the public were not involved in the design, conduct, reporting or dissemination plans of our research.

\section{RESULTS}

Two hundred six patients with diabetes were recruited, all of Rwandan nationality. One patient was excluded from the analysis for not completing the D-39 questionnaire. The sample characteristics are presented in table 1 . Most of them were women $(64.4 \%)$, aged 55 years or younger $(59.8 \%)$, married $(59.6 \%)$, and resided in $\mathrm{rural} / \mathrm{semi}$ urban areas $(70.6 \%)$. There was a higher percentage of participants without formal education or with a primary school degree in rural/semi-urban areas than in urban centres $(73.2 \%$ vs $51.7 \%)$. Moreover, unemployment was higher in rural/semi-urban areas than in urban centres ( $45.8 \%$ vs $36.7 \%$, respectively).

Most participants had been diagnosed with type 2 diabetes. The majority of the patients had had diabetes for up to 5 years $(54.7 \%)$, while $15.8 \%$ had been diagnosed with the disease for more than 10 years. There were only five patients with missing HbAlc. Regarding glycaemic control, $29.5 \%$ of the patients had an HbAlc above $8 \%$, while an additional $27.5 \%$ had an HbAlc between $7 \%$ and $8 \%$. Approximately two-thirds of the patients were on oral antidiabetic medications. Most patients rated their health as moderate $(54.9 \%)$ and their perceived overall quality of life as average (34.6\%). The perceived severity of their disease had a median of $4(\mathrm{IQR}=3-5)$, as evaluated on the 7-point Likert scale.

No patient had more than four missing values in D-39, and there were no patients for whom an entire dimension was excluded from the analysis due to numerous missing items. There were only eight missing values scattered throughout six patients. The mean scores of the five D-39 domains, and their differences between and correlations with sociodemographic variables are presented in table 2. There were gender and age differences on the 'sexual functioning' and 'energy and mobility' scales. Poorer scores in the 'social burden' and 'energy and mobility' dimensions were apparent in participants without formal education or a primary school degree. There was a weak inverse correlation between education and the 'anxiety and worry' dimension. There were no differences across the types of residential areas and employment status. 


\section{Table 1 Sample characteristics}

Gender, n (\%)

\begin{tabular}{|c|c|}
\hline Female & $132(64.39)$ \\
\hline Male & $73(35.61)$ \\
\hline Age, mean (SD), median (IQR) & 51.22 (12.98), 52 (42-61) \\
\hline \multicolumn{2}{|l|}{ Marital status, n (\%) } \\
\hline Single & $20(9.85)$ \\
\hline Married & $121(59.61)$ \\
\hline Cohabitating partnership & $31(15.27)$ \\
\hline Divorced & $4(1.97)$ \\
\hline Widowed & $27(13.30)$ \\
\hline \multicolumn{2}{|l|}{ Most usual living situation, n (\%) } \\
\hline Lives alone & $5(2.49)$ \\
\hline $\begin{array}{l}\text { Has other people living with } \\
\text { him/her }\end{array}$ & $196(97.51)$ \\
\hline $\begin{array}{l}\text { Number of people living with } \\
\text { him/her, mean (SD), median } \\
\text { (IQR) }\end{array}$ & $4.86(2.22), 5(3-6)$ \\
\hline
\end{tabular}

Area of residency, $\mathrm{n}(\%)$

$\begin{array}{ll}\text { Urban } & 60(29.41) \\ \text { Semi-urban } & 51(25.00) \\ \text { Rural } & 93(45.59)\end{array}$

Years of completed education, 7.50 (3.19), 6 (6-9) mean (SD), median (IQR)

\begin{tabular}{|c|c|}
\hline \multicolumn{2}{|l|}{ Highest degree obtained, n (\%) } \\
\hline No formal education & $21(10.34)$ \\
\hline Primary school & $115(56.65)$ \\
\hline Secondary school & $42(20.69)$ \\
\hline University degree & $7(3.45)$ \\
\hline Vocational school & $18(8.87)$ \\
\hline \multicolumn{2}{|l|}{ Employment status, n (\%) } \\
\hline Unemployed & $88(42.93)$ \\
\hline Employed & $101(49.27)$ \\
\hline Retired & $16(7.80)$ \\
\hline \multicolumn{2}{|l|}{ Abilities, mean (SD), median $(\mathrm{IQR})^{*}$} \\
\hline Writing & 3.37 (0.60), 3 (3-4) \\
\hline Read and understand & $3.40(0.58), 3(3-4)$ \\
\hline $\begin{array}{l}\text { Converse with other people } \\
\text { and understand }\end{array}$ & $3.68(0.48), 4(3-4)$ \\
\hline Hear clearly & $3.72(0.46), 4(3-4)$ \\
\hline See things clearly & $3.41(0.57), 3(3-4)$ \\
\hline Do normal daily activities & 3.39 (0.68), $3.5(3-4)$ \\
\hline $\begin{array}{l}\text { Move about the community } \\
\text { by himself/herself }\end{array}$ & $3.69(0.48), 4(3-4)$ \\
\hline $\begin{array}{l}\text { Self-rated overall health, mean } \\
(\mathrm{SD}) \text {, median }(\mathrm{IQR}) \dagger\end{array}$ & 3.39 (0.59), 3 (3-4) \\
\hline \multicolumn{2}{|l|}{ Types of diabetes, n (\%) } \\
\hline Type I & $20(10.10)$ \\
\hline Type II & $178(89.90)$ \\
\hline
\end{tabular}

Continued

\begin{tabular}{|c|c|}
\hline $\begin{array}{l}\text { Years of duration of diabetes, } \\
\text { mean (SD), median (IQR) }\end{array}$ & $6.33(5.82), 5(2-8)$ \\
\hline \multicolumn{2}{|l|}{ Number of complications, $\mathrm{n}(\%) \ddagger$} \\
\hline No complications & $156(78.00)$ \\
\hline 1 complication & $38(19.00)$ \\
\hline 2 or more complications & $6(3.00)$ \\
\hline \multicolumn{2}{|c|}{ Reported episodes of hypoglycaemia, n (\%) } \\
\hline Yes & $13(6.47)$ \\
\hline No & $188(93.53)$ \\
\hline \multicolumn{2}{|l|}{ Presence of comorbidities, $\mathrm{n}(\%)$} \\
\hline No comorbidities & 86 (41.95) \\
\hline 1 comorbidity & $82(40.00)$ \\
\hline 2 or more comorbidities & $37(18.05)$ \\
\hline \multicolumn{2}{|l|}{ Type of comorbidities, $\mathrm{n}(\%) \S$} \\
\hline Hypertension & $97(47.32)$ \\
\hline HIV infection & $16(7.80)$ \\
\hline Chronic neck or back pain & $12(5.85)$ \\
\hline Hepatitis C & $11(5.37)$ \\
\hline Rheumatoid arthritis & $11(5.37)$ \\
\hline Asthma & $3(1.46)$ \\
\hline \multicolumn{2}{|l|}{ Type of therapy, $n$ (\%) } \\
\hline No therapy & $4(1.95)$ \\
\hline Oral antidiabetic drugs only & $136(66.34)$ \\
\hline Insulin only & $60(29.27)$ \\
\hline $\begin{array}{l}\text { Oral antidiabetic drugs and } \\
\text { insulin }\end{array}$ & $5(2.44)$ \\
\hline $\begin{array}{l}\text { HbA1c, mean (SD), median } \\
\text { (IQR) }\end{array}$ & 7.66 (2.09), 7.3 (6.4 \\
\hline
\end{tabular}

*Abilities were evaluated using a 4-point Likert scale ranging from 1 (cannot do at all) to 4 (can do very well).

†Overall health was assessed using a 5-point Likert scale ranging from 1 (very poor) to 5 (very good).

$\ddagger$ Complications included: nephropathy, retinopathy, neuropathy, peripheral vascular disease, myocardial ischaemia and stroke. $\S$ The six most frequent comorbidities are reported in this table. HbA1c, glycated haemoglobin.

Associations of the D-39 domains with clinical variables are presented in table 3. Patients with more than 5 years of duration of diabetes reported a greater perceived severity of their illness $($ mean $=4.04, \mathrm{SD}=1.41)$ compared with those with a duration of 5 years or less (mean=3.62, $\mathrm{SD}=1.37 ; \mathrm{r}=-0.165, \mathrm{p}=0.018$ ). The 'anxiety and worry' scores differed across the groups of patients with different years of diabetes duration; however, in the post-hoc contrasts and after adjustment of the level of significance for multiple comparisons, no significant differences remained.

The 'energy and mobility' dimension differed across the groups of complications and comorbidities. In the post-hoc contrasts, using an adjusted level of significance 
Table 2 The five dimensions of D-39 and their correlations with and differences between sociodemographic variables

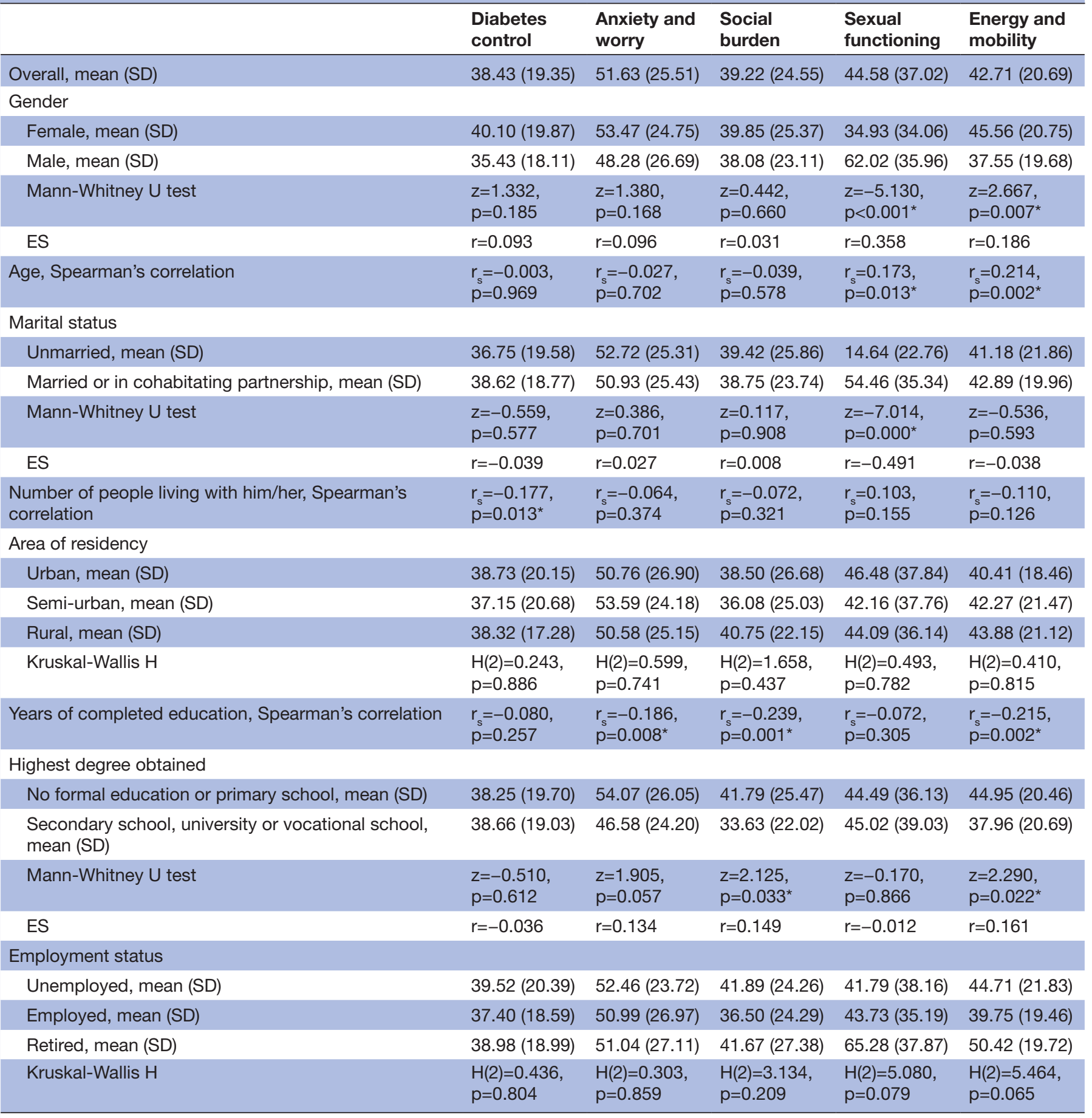

*Significant at $\mathrm{p} \leq 0.05$

D-39, Diabetes-39; ES, effect size.

of 0.0167 , worse scores were noted in patients with one complication $(\mathrm{z}=-2.517, \mathrm{r}=-0.181, \mathrm{p}=0.011)$ and with two or more complications $(\mathrm{z}=-2.799, \mathrm{r}=-0.220, \mathrm{p}=0.003)$ when compared with those without any complication. No difference was observed, however, between those having one and two or more complications $(\mathrm{z}=-1.505$, $\mathrm{r}=-0.227, \mathrm{p}=0.137)$. Furthermore, it appeared that 'energy and mobility' was significantly worse in participants with two or more comorbidities compared with those without any comorbidities $(\mathrm{z}=-3.141, \mathrm{r}=-0.283$, $\mathrm{p}=0.001)$. Yet, it should be noted that participants with just one comorbidity yielded no significant score difference when compared with those without any comorbidities $(\mathrm{z}=-1.746, \mathrm{r}=-0.135, \mathrm{p}=0.081)$ or with those with two or more comorbidities $(\mathrm{z}=-1.918, \mathrm{r}=-0.176, \mathrm{p}=0.055)$.

Table 4 presents the results of the multiple regression analysis. All models for the five dimensions were statistically significant. The HbA1c target of $7 \%$ was a predictor 
Table 3 The five dimensions of D-39 and their correlations with and differences between clinical variables

\begin{tabular}{|c|c|c|c|c|c|}
\hline & $\begin{array}{l}\text { Diabetes } \\
\text { control }\end{array}$ & $\begin{array}{l}\text { Anxiety and } \\
\text { worry }\end{array}$ & $\begin{array}{l}\text { Social } \\
\text { burden }\end{array}$ & $\begin{array}{l}\text { Sexual } \\
\text { functioning }\end{array}$ & $\begin{array}{l}\text { Energy and } \\
\text { mobility }\end{array}$ \\
\hline \multicolumn{6}{|l|}{ Types of diabetes } \\
\hline Type I, mean (SD) & $38.68(20.87)$ & $58.13(24.80)$ & $43.17(25.65)$ & 33.06 (42.94) & $35.83(20.13)$ \\
\hline Type II, mean (SD) & $38.37(19.41)$ & $51.36(25.58)$ & $38.39(24.47)$ & $45.91(36.24)$ & $43.32(20.70)$ \\
\hline Mann-Whitney U test & $\begin{array}{l}z=0.076 \\
p=0.941\end{array}$ & $\begin{array}{l}z=1.065 \\
p=0.289\end{array}$ & $\begin{array}{l}z=0.690 \\
p=0.494\end{array}$ & $\begin{array}{l}\mathrm{z}=-1.528 \\
\mathrm{p}=0.127\end{array}$ & $\begin{array}{l}z=-1.519 \\
p=0.130\end{array}$ \\
\hline ES & $r=0.005$ & $r=0.076$ & $r=0.049$ & $r=-0.109$ & $r=-0.108$ \\
\hline $\begin{array}{l}\text { Years of duration of diabetes, Spearman's } \\
\text { correlation }\end{array}$ & $\begin{array}{l}r_{s}=0.030 \\
p=0.667\end{array}$ & $\begin{array}{l}r_{s}=0.119 \\
p=0.092\end{array}$ & $\begin{array}{l}r_{s}=0.133 \\
p=0.059\end{array}$ & $\begin{array}{l}r_{s}=0.022 \\
p=0.751\end{array}$ & $\begin{array}{l}r_{s}=0.093 \\
p=0.188\end{array}$ \\
\hline \multicolumn{6}{|l|}{ Years of duration of diabetes } \\
\hline Up to 2 years, mean (SD) & $35.14(17.28)$ & $45.42(24.20)$ & 34.06 (22.99) & $42.96(33.63)$ & 39.78 (21.49) \\
\hline $3-5$ years, mean (SD) & $40.71(19.24)$ & $55.39(25.40)$ & $39.93(25.63)$ & $46.62(39.41)$ & $42.70(17.62)$ \\
\hline 6 or more years, mean (SD) & $39.33(20.80)$ & $53.57(25.84)$ & $41.58(24.44)$ & $43.22(37.97)$ & $43.77(21.36)$ \\
\hline Kruskal Wallis $\mathrm{H}$ & $\begin{array}{l}\mathrm{H}(2)=2.233 \\
\mathrm{p}=0.327\end{array}$ & $\begin{array}{l}H(2)=5.977 \\
p=0.050^{*}\end{array}$ & $\begin{array}{l}H(2)=3.347 \\
p=0.188\end{array}$ & $\begin{array}{l}H(2)=1.164 \\
p=0.921\end{array}$ & $\begin{array}{l}\mathrm{H}(2)=1.821 \\
\mathrm{p}=0.402\end{array}$ \\
\hline \multicolumn{6}{|l|}{ Number of complications } \\
\hline No complications, mean (SD) & 37.69 (19.39) & $50.61(25.59)$ & $38.18(24.03)$ & $43.20(35.88)$ & $40.28(19.85)$ \\
\hline 1 complication, mean (SD) & $40.17(20.62)$ & $54.17(26.69)$ & $39.82(26.88)$ & $55.12(40.34)$ & $50.44(22.34)$ \\
\hline 2 or more complications, mean (SD) & $48.15(16.16)$ & $59.72(21.84)$ & $55.56(17.08)$ & $29.63(37.13)$ & $63.15(12.77)$ \\
\hline Kruskal Wallis $\mathrm{H}$ & $\begin{array}{l}\mathrm{H}(2)=2.242 \\
\mathrm{p}=0.326\end{array}$ & $\begin{array}{l}H(2)=1.356 \\
p=0.507\end{array}$ & $\begin{array}{l}H(2)=3.506 \\
p=0.173\end{array}$ & $\begin{array}{l}\mathrm{H}(2)=4.155 \\
\mathrm{p}=0.125\end{array}$ & $\begin{array}{l}H(2)=12.997 \\
p=0.001^{*}\end{array}$ \\
\hline \multicolumn{6}{|l|}{ Presence of comorbidities } \\
\hline No comorbidities, mean (SD) & $37.42(19.74)$ & $47.53(25.62)$ & $35.66(22.91)$ & $42.05(36.25)$ & $38.28(20.81)$ \\
\hline 1 comorbidity, mean (SD) & $39.33(18.31)$ & $55.34(25.85)$ & $40.16(26.19)$ & $44.92(37.57)$ & $43.28(19.21)$ \\
\hline 2 or more comorbidities, mean (SD) & $38.81(21.04)$ & $52.93(23.73)$ & $45.41(23.68)$ & 49.70 (38.02) & $51.74(21.01)$ \\
\hline Kruskal Wallis $\mathrm{H}$ & $\begin{array}{l}\mathrm{H}(2)=0.616 \\
\mathrm{p}=0.735\end{array}$ & $\begin{array}{l}H(2)=4.128 \\
p=0.127\end{array}$ & $\begin{array}{l}H(2)=3.815 \\
p=0.149\end{array}$ & $\begin{array}{l}H(2)=1.457 \\
p=0.483\end{array}$ & $\begin{array}{l}H(2)=10.572 \\
p=0.005^{*}\end{array}$ \\
\hline \multicolumn{6}{|l|}{ Presence of hypertension } \\
\hline Without hypertension, mean (SD) & $37.14(18.92)$ & $48.30(24.25)$ & $35.59(22.45)$ & $40.95(36.43)$ & 39.35 (20.05) \\
\hline With hypertension, mean (SD) & $39.88(19.82)$ & $55.33(26.49)$ & $43.26(26.21)$ & $48.63(37.44)$ & $46.45(20.86)$ \\
\hline Mann-Whitney U test & $\begin{array}{l}z=-0.804 \\
p=0.422\end{array}$ & $\begin{array}{l}z=-1.949 \\
p=0.051\end{array}$ & $\begin{array}{l}z=-1.925 \\
p=0.054\end{array}$ & $\begin{array}{l}z=-1.636 \\
p=0.102\end{array}$ & $\begin{array}{l}\mathrm{z}=-2.343 \\
\mathrm{p}=0.019^{*}\end{array}$ \\
\hline ES & $r=-0.056$ & $r=-0.136$ & $r=-0.134$ & $r=-0.114$ & $r=-0.164$ \\
\hline \multicolumn{6}{|l|}{ Presence of HIV infection } \\
\hline Without HIV infection, mean (SD) & $31.86(13.69)$ & $46.62(21.53)$ & $39.37(20.04)$ & $43.40(38.61)$ & $42.43(17.15)$ \\
\hline With HIV infection, mean (SD) & $38.99(19.68)$ & $52.05(25.83)$ & $39.21(24.94)$ & 44.68 (36.99) & $42.73(21.00)$ \\
\hline Mann-Whitney U test & $\begin{array}{l}z=-1.565 \\
p=0.118\end{array}$ & $\begin{array}{l}z=-0.866 \\
p=0.391\end{array}$ & $\begin{array}{l}z=0.204 \\
p=0.840\end{array}$ & $\begin{array}{l}\mathrm{z}=-0.192 \\
\mathrm{p}=0.851\end{array}$ & $\begin{array}{l}z=0.000 \\
p=1.000\end{array}$ \\
\hline ES & $r=-0.109$ & $r=0-.060$ & $r=0.014$ & $r=-0.013$ & $r=0.000$ \\
\hline \multicolumn{6}{|l|}{ Type of therapy } \\
\hline Oral antidiabetic drugs, mean (SD) & $37.38(18.70)$ & $50.03(25.47)$ & $37.65(24.20)$ & $46.85(36.67)$ & 42.39 (19.90) \\
\hline Insulin or combination, mean (SD) & $40.36(20.69)$ & $55.00(26.13)$ & $41.54(24.78)$ & $40.09(37.47)$ & $43.16(22.74)$ \\
\hline Mann-Whitney U test & $\begin{array}{l}z=-0.935 \\
p=0.351\end{array}$ & $\begin{array}{l}z=-1.302 \\
p=0.194\end{array}$ & $\begin{array}{l}z=-0.990 \\
p=0.323\end{array}$ & $\begin{array}{l}z=1.261 \\
p=0.208\end{array}$ & $\begin{array}{l}z=0.035 \\
p=0.973\end{array}$ \\
\hline ES & $r=-0.066$ & $r=-0.092$ & $r=-0.070$ & $r=0.089$ & $r=0.002$ \\
\hline HbA1c, Spearman's correlation & $\begin{array}{l}r_{s}=0.088 \\
p=0.212\end{array}$ & $\begin{array}{l}r_{s}=0.062, \\
p=0.383\end{array}$ & $\begin{array}{l}r_{s}=0.031 \\
p=0.666\end{array}$ & $\begin{array}{l}r_{s}=-0.100 \\
p=0.159\end{array}$ & $\begin{array}{l}r_{s}=0.012, \\
p=0.863\end{array}$ \\
\hline
\end{tabular}


Table 3 Continued

\begin{tabular}{lllll}
$\begin{array}{l}\text { Diabetes } \\
\text { control }\end{array}$ & $\begin{array}{l}\text { Anxiety and } \\
\text { worry }\end{array}$ & $\begin{array}{l}\text { Social } \\
\text { burden }\end{array}$ & $\begin{array}{l}\text { Sexual } \\
\text { functioning }\end{array}$ & $\begin{array}{l}\text { Energy and } \\
\text { mobility }\end{array}$ \\
\hline
\end{tabular}

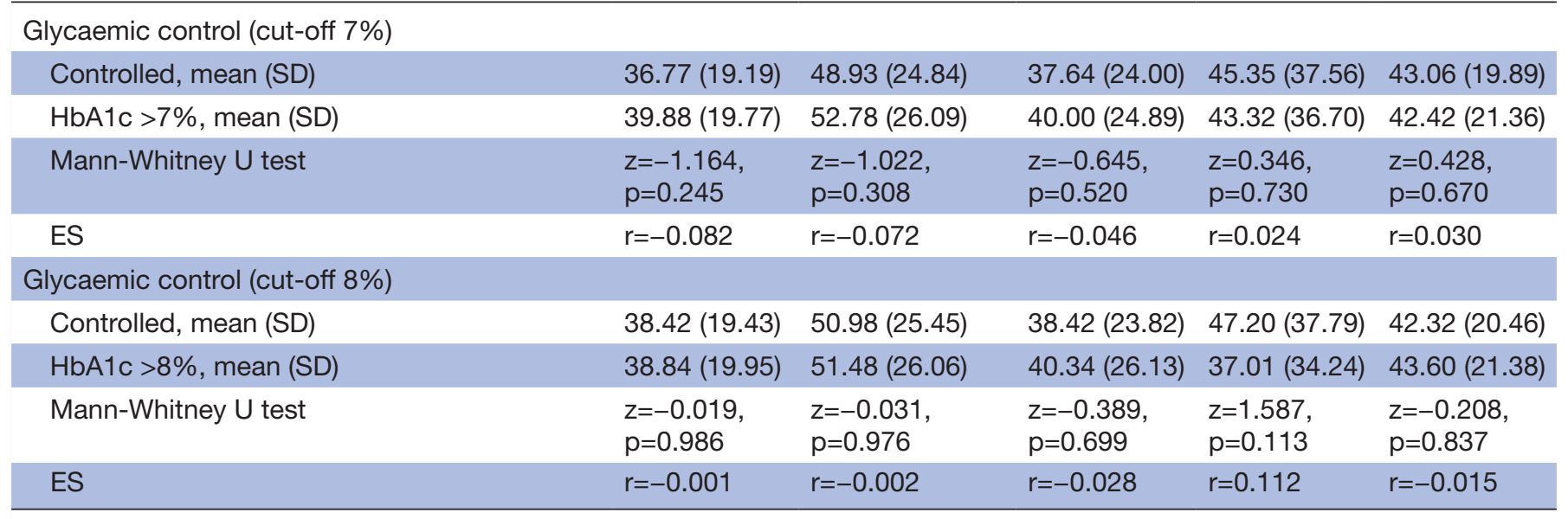

*Significant at $\mathrm{p} \leq 0.05$

D-39, Diabetes-39; ES, effect size; HbA1c, glycated haemoglobin.

of 'diabetes control'; however, this relationship was moderated by insulin treatment, as indicated by the interaction effect. There was an additional interaction effect between female gender and presence of hypertension. 'Anxiety and worry' was predicted by hypertension and educational degree; the latter was moderated by the effect of age. 'Social burden' was associated with age, years of completed education and hypoglycaemic episodes. An interaction effect between gender and hypertension was also observed. Gender was also a predictor for the 'sexual functioning' scale moderated by age. Finally, the presence of complications and the years of completed education were associated with the 'energy and mobility' scale, while there was a moderating effect between years of duration of diabetes and age.

\section{DISCUSSION}

To the best of our knowledge, this is the first study reporting on quality of life in adult patients with diabetes in Rwanda. The worst affected dimensions were the 'anxiety and worry', 'sexual functioning' and 'energy and mobility' scales, in accordance with the findings reported in a study among patients with diabetes in Swaziland. ${ }^{16}$

In line with previous findings, there were no differences in any of the dimensions of D-39 between patients with type 1 and type 2 diabetes. ${ }^{16}$ Several studies report an association between longer duration of illness and worse quality of life, ${ }^{153435}$ although there are also contradicting findings. ${ }^{101636-38}$ In patients with type 2 diabetes, a combination of factors may explain this association: a deterioration in beta-cell functioning over time; a pressing requirement to attain glycaemic control, more intense disease management, behaviour modification, and a complex medication regimen, including insulin; an increase in complications, and a decrease in treatment adherence. ${ }^{34-41}$ In the present sample, however, there was no correlation between duration of the disease and the D-39 dimensions. Nevertheless, a moderating effect was noted in the 'energy and mobility' dimension, with the disease duration impacting the scale more strongly the older the participant was.

In contrast to studies reporting improved quality of life in patients with better glycaemic control, ${ }^{42}$ in the present study, neither HbAlc values nor maintaining glycaemic control with HbA1c values of $8 \%$ or below was associated with any of the scales. Moreover, several studies found a negative association between insulin use and quality of life. ${ }^{91643}$ The present results, however, do not support this notion as there were no differences in the five scales between patients treated with insulin and those on oral medication, even when limiting the analysis to participants with documented type 2 diabetes. Nonetheless, a moderating effect was identified between treatment type (oral antidiabetic drugs vs insulin alone or combined) and achieving the target of HbAlc of $7 \%$ or below, in that the use of insulin negatively affected the 'diabetes control' dimension in patients with HbAlc of $7 \%$ or below. This finding is consistent with the interaction reported in another study on patients with type 2 diabetes. ${ }^{39}$ Although the use of insulin can help decrease acute and long-term complications, its complex management and fear of hypoglycaemia, together with the more intense disease management and behaviour modifications required from those wanting to achieve a desired glycaemic control, could greatly worsen quality of life. ${ }^{539}$

It should be noted, however, that due to resource restrictions and lack of portable blood glucose metres, monitoring of diabetes commonly takes place only in clinical settings, especially in rural areas. ${ }^{2}$ Moreover, although regular $\mathrm{HbAlc}$ testing is recommended and hospitals are 
Table 4 Sociodemographic and clinical predictors of the five dimensions of the D-39 questionnaire

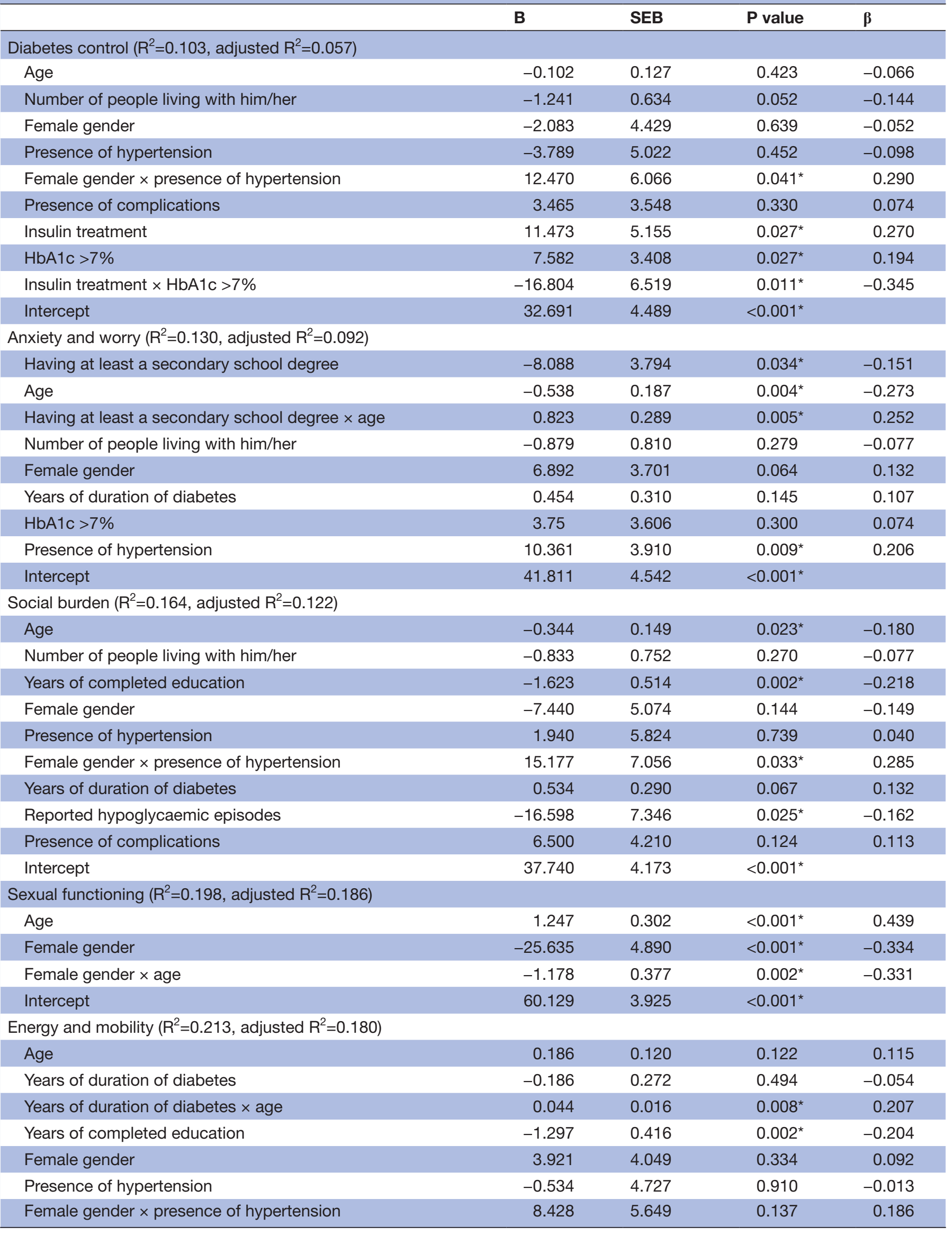


Table 4 Continued

\begin{tabular}{lrrrr}
\hline & B & SEB & P value & $\boldsymbol{\beta}$ \\
\hline Presence of complications & 9.972 & 3.325 & $0.003^{*}$ & 0.204 \\
Intercept & 34.603 & 3.399 & $<0.001^{*}$ & \\
\hline
\end{tabular}

*Significant at $\mathrm{p} \leq 0.05$

D-39, Diabetes-39; HbA1c, glycated haemoglobin; SEB, Standard Error of B.

able to perform the test either at their laboratories or with point-of-care analysers, the lack of reagents often prevents testing on a regular basis. As a consequence, there is a limited number of studies reporting on glycaemic control in the country. A retrospective review in patients with HbA1c above $6.5 \%$ between 2006 and 2014 reported a median HbA1c of $10.3 \% .{ }^{44}$ A clinical trial found an $\mathrm{HbAlc}$ of $8.98 \%$ at baseline, with only $15.7 \%$ of the participants with an HbA1c of $7 \%$ or below. ${ }^{25}$ Increased access to and availability of HbAlc testing can improve glycaemic control as a result of improved patient adherence and provider attitudes, knowledge and practice, who, for example, may otherwise be more conservative with medication regimen to avert hypoglycaemic episodes. ${ }^{245}$ In the present study, reporting hypoglycaemic episodes was only a predictor of more 'social burden'.

Poor glycaemic control has also been associated with a high number of diabetes-related complications. ${ }^{25}$ In turn, complications have been shown to impact all aspects of quality of life, irrespective of the type of diabetes. ${ }^{4}$ They contribute to the deterioration of physical, psychological and social aspects, such as limiting the ability to carry out daily activities, causing physical impairments and pain, prompting general emotional distress and depression, and interfering with interpersonal relations. ${ }^{4} 1434$ 46-48 $\mathrm{In}$ the present sample, complications were associated with a worse score on the 'energy and mobility' dimension. It should be noted, however, that the number of complications in this study was significantly lower than previously reported. ${ }^{49}$ Under-reporting may have been a result of patient records not being kept up-to-date, and of complications, such as nephropathy, not having been accurately registered. ${ }^{4450}$ The most frequent complication of all, retinopathy, was present in $13.6 \%$ of the sample, followed by neuropathy $(8.1 \%)$. Rwanda's guidelines for the management of non-communicable diseases indicate an annual referral for ophthalmological examination, ${ }^{24}$ which may have been a contributing factor to recording retinopathy in patient files.

In patients with diabetes, comorbidity has previously been identified as a predictor of worse quality of life. ${ }^{1316}$ A study in South Africa estimated a comorbidity prevalence of $65.2 \%$ in primary healthcare patients with diabetes, and a prevalence of hypertension of $63.1 \%$ in patients with type 2 diabetes. ${ }^{51}$ In our study, $58.1 \%$ of the patients had at least one comorbid condition. The most frequently documented comorbid conditions of our sample were hypertension and HIV infection $(47.3 \%$ and $7.8 \%$, respectively). As in the case of complications, there may be a certain degree of under-reporting for the comorbidities; however, the prevalence of hypertension and HIV infection is similar to what Amendezo et al found in a Rwandan sample previously (49.0\% hypertension and 5.6\% HIV).$^{25}$ Patients with hypertension $(54.8 \%$ of the men and $43.2 \%$ of the women) presented worse scores in the 'energy and mobility' $(\mathrm{p}=0.019, \mathrm{r}=-0.164)$ scale of the D-39. A recent meta-analysis in patients with type 2 diabetes associated the presence of hypertension with poorer 'physical functioning' in the 36-Item Short Form Survey questionnaire. ${ }^{34}$

Consistent with other studies employing the D- $39,{ }^{9} 52$ women in our sample reported being affected less on 'sexual functioning' compared with men (score of 34.93 vs 62.02, respectively). An interaction effect was observed between gender and age on this scale. There was a strong negative effect of age on the 'sexual functioning' scale in male patients, in that the older the male participant, the worse the score was. The association between male sexual dysfunction and diabetes has been known for some time. ${ }^{43}$ Gender differences in behaviour, beliefs and attitudes towards a disease could have a larger impact on sexual functioning in men. ${ }^{9}$ Nonetheless, sociocultural factors and the setting effect should also be considered, as women may not have been comfortable with rating such aspects as sexual activity, while visiting a public setting. ${ }^{53}$ This interpretation is supported by the moderating effect of gender and hypertension on the 'diabetes control' and 'social burden' scales, in that hypertension had a stronger adverse effect on the two scales in women.

Previous studies have identified low income as a predictor of worse diabetes-specific quality of life. ${ }^{9} 53$ Although it was not possible to investigate participants' income, we identified a small difference in overall perceived quality of life, as rated by the single 7-point questionnaire item, between unemployed and employed participants (mean $=3.50$ vs 4.08 , respectively; $\mathrm{z}=-3.234$, $\mathrm{r}=-0.235, \mathrm{p}=0.001$ with adjusted level of significance of $0.025)$. Furthermore, having a higher education degree predicted better scores on the 'social burden' and 'energy and mobility' scales. It is plausible to assume that education plays a significant role for self-care and self-management of the disease, as well as the individual's financial situation and access to care. ${ }^{12} 1654$ Interestingly, an interaction between age and education on the 'anxiety and worry' dimension was also identified: having no formal education or a primary school degree had a 
stronger negative effect on the 'anxiety and worry' scale in younger participants.

Several limitations of the present study must be acknowledged. First, the study included both types of diabetes, as their distinction is complicated by variant forms of the disease, possible existing misclassification and lack of c-peptide testing. ${ }^{455} 56$ Although the percentage of patients with type 2 diabetes $(89.9 \%)$ was similar to the prevalence reported elsewhere ${ }^{44}$ there was an insufficient number of participants to explore differences between diabetes types. Second, our sample was likely not representative of the general population, as the hospitals participating in the clinical trial had already been preselected by third parties according to different criteria. ${ }^{23}$ It is also possible that some patients with severe conditions may not have been included in the present sample. Nonetheless, it should be noted that the newly established programme of community health workers (Home-based Care Practitioners) facilitated linking patients with healthcare services for the management of non-communicable diseases including outpatient clinics. Moreover, during the pre-enrolment screening, we invited the nurses of health centres to refer patients to the outpatient clinics. Patients with severe hearing and visual impairments and severe mental health conditions, however, were excluded, as the appropriateness of the use of the questionnaire in these groups of patients remains unclear. Third, the limited sample size may also explain the low $\mathrm{R}^{2}$ that was observed in the five dimensions of the questionnaire. Fourth, we were unable to evaluate withinsubject changes in quality of life and establish causal relations across different factors due to the cross-sectional nature of the study. Finally, our study employed only a disease-specific instrument for the assessment of quality of life. Although the combination with a generic qualityof-life questionnaire could have captured additional universal aspects and would have enabled comparisons with patients with other diseases, ${ }^{757}$ there was a need to limit the time required from respondents participating in the baseline assessment of the clinical trial.

Our study is the first to report on quality of life in patients living with diabetes in Rwanda. 'Anxiety and worry', followed by 'sexual functioning', were the two most affected dimensions. Overall, the five dimensions of quality of life were predicted differentially by gender, age, years of education, achieving a HbA1c of $7 \%$, hypertension, presence of complications and hypoglycaemic episodes. Further prospective studies with larger samples are necessary to attain a broader insight into factors that can prevent quality of life from deteriorating in patients living with diabetes.

\section{Twitter Charilaos Lygidakis @lygidakis and Per Kallestrup @PerKallestrup}

Acknowledgements First, we would like to acknowledge the Ministry of Health of Rwanda for their support and contribution to the study. Second, we would like to thank the personnel of the NCD division at the Rwanda Biomedical Center (RBC) for their support in organising and conducting the study in Rwanda. Finally, we also wish to extend our gratitude to Mireille Uwineza, Marie Rose Uwizeye, Anastase
Nzeyimana, Esperance Mukangango and Hortense Umurerwa, for their support in the data collection.

Contributors CL, JPU, CV and PK conceived of the study and developed the design and protocol. CL wrote the first draft of the manuscript and conducted statistical analyses. CL and JPU overviewed the data collection and worked on drafts of the manuscript. MB made substantial contributions to the statistical analysis. FU made considerable contributions to the manuscript. All authors contributed to revising it critically.

Funding Funding for the D2Rwanda Study was provided by the Karen Elise Jensens Fond, and the Universities of Luxembourg and Aarhus.

Competing interests None declared.

Patient consent for publication Not required.

Ethics approval The study received ethical approval from the Rwanda National Ethics Committee (100/RNEC/2017; renewed in 113/RNEC/2018 and 192/ RNEC/2019; amended in 463/RNEC/2017 and 688/RNEC/2019), and the Ethics Review Panel of the University of Luxembourg (ERP 17-014 D2Rwanda; amended in ERP 17-048 D2Rwanda).

Provenance and peer review Not commissioned; externally peer reviewed.

Data availability statement Data may be obtained from a third party and are not publicly available. The data used to support the findings of this study are restricted by the government of Rwanda and cannot be released or shared partially or totally with third parties without the written permission of the Rwanda Biomedical Center. Data are available from the corresponding author for researchers who meet the criteria for access to confidential data, and only after authorisation from the Rwanda Biomedical Center.

Open access This is an open access article distributed in accordance with the Creative Commons Attribution Non Commercial (CC BY-NC 4.0) license, which permits others to distribute, remix, adapt, build upon this work non-commercially, and license their derivative works on different terms, provided the original work is properly cited, appropriate credit is given, any changes made indicated, and the use is non-commercial. See: http://creativecommons.org/licenses/by-nc/4.0/.

\section{ORCID iD}

Charilaos Lygidakis http://orcid.org/0000-0003-2571-6286

\section{REFERENCES}

1 International Diabetes Federation (IDF). IDF diabetes atlas. 9th edn Brussels, Belgium: International Diabetes Federation, 2019.

2 Park PH, Pastakia SD. Access to hemoglobin A1c in rural Africa: a difficult reality with severe consequences. J Diabetes Res 2018;2018:1-5.

3 Yang W, Zhao W, Xiao J, et al. Medical care and payment for diabetes in China: enormous threat and great opportunity. PLoS One 2012;7:e39513.

4 Trikkalinou A, Papazafiropoulou AK, Melidonis A. Type 2 diabetes and quality of life. World J Diabetes 2017;8:120-9.

5 Rubin RR, Peyrot M. Quality of life and diabetes. Diabetes Metab Res Rev 1999;15:205-18.

6 El Achhab Y, Nejjari C, Chikri M, et al. Disease-specific health-related quality of life instruments among adults diabetic: a systematic review. Diabetes Res Clin Pract 2008;80:171-84.

7 Speight J, Reaney MD, Barnard KD. Not all roads lead to Rome-a review of quality of life measurement in adults with diabetes. Diabet Med 2009;26:315-27.

8 Kruk ME, Nigenda G, Knaul FM. Redesigning primary care to tackle the global epidemic of noncommunicable disease. Am J Public Health 2015;105:431-7.

9 Khunkaew S, Fernandez R, Sim J. Demographic and clinical predictors of health-related quality of life among people with type 2 diabetes mellitus living in northern Thailand: a cross-sectional study. Health Qual Life Outcomes 2019;17:177.

10 Redekop WK, Koopmanschap MA, Stolk RP, et al. Health-Related quality of life and treatment satisfaction in Dutch patients with type 2 diabetes. Diabetes Care 2002;25:458-63.

11 Thapa S, Pyakurel P, Baral DD, et al. Health-Related quality of life among people living with type 2 diabetes: a community based crosssectional study in rural Nepal. BMC Public Health 2019;19:1171.

12 Werfalli M, Kassanjee R, Kalula S, et al. Diabetes in South African older adults: prevalence and impact on quality of life and functional disability - as assessed using SAGE Wave 1 data. Glob Health Action 2018;11:1449924. 
13 Wee H-L, Cheung Y-B, Li S-C, et al. The impact of diabetes mellitus and other chronic medical conditions on health-related quality of life: is the whole greater than the sum of its parts? Health Qual Life Outcomes 2005;3:2.

14 Hermanns N, Kulzer B, Krichbaum M, et al. How to screen for depression and emotional problems in patients with diabetes: comparison of screening characteristics of depression questionnaires, measurement of diabetes-specific emotional problems and standard clinical assessment. Diabetologia 2006;49:469-77.

15 Al Hayek AA, Robert AA, Al Saeed A, et al. Factors associated with health-related quality of life among Saudi patients with type 2 diabetes mellitus: a cross-sectional survey. Diabetes Metab J 2014;38:220-9.

16 Mngomezulu N, Yang C-C. Quality of life and its correlates in diabetic outpatients in Swaziland. Int Health 2015;7:464-71.

17 Gross CC, Scain SF, Scheffel R, et al. Brazilian version of the problem areas in diabetes scale (B-PAID): validation and identification of individuals at high risk for emotional distress. Diabetes Res Clin Pract 2007;76:455-9.

18 Arifin $B$, Idrus LR, van Asselt ADI, et al. Health-related quality of life in Indonesian type 2 diabetes mellitus outpatients measured with the Bahasa version of EQ-5D. Qual Life Res 2019;28:1179-90.

19 National Institute of Statistics of Rwanda (NISR), National Institute of Statistics of Rwanda. The statistical Yearbook, 2019 edition, 2019. Available: http://www.statistics.gov.rw/publication/statisticalyearbook-2019

20 Uwimana J, Struthers P. Met and unmet palliative care needs of people living with HIV/AIDS in Rwanda. Sahara J 2007;4:575-85.

21 Biraguma J, Mutimura E, Frantz JM. Health-Related quality of life and associated factors in adults living with HIV in Rwanda. Sahara J 2018;15:110-20.

22 Krumme AA, Kaigamba F, Binagwaho A, et al. Depression, adherence and attrition from care in HIV-infected adults receiving antiretroviral therapy. J Epidemiol Community Health 2015;69:284-9.

23 Lygidakis C, Uwizihiwe JP, Kallestrup P, et al. Community- and $\mathrm{mHealth}$-based integrated management of diabetes in primary healthcare in Rwanda ( $D^{2} R$ wanda): the protocol of a mixed-methods study including a cluster randomised controlled trial. BMJ Open 2019;9:e028427.

24 Ministry of Health of Rwanda, Rwanda Biomedical Center (RBC). National guideline for management of non communicable diseases (NCDS). 2016th ED. Kigali, 2016. Available: http://ncdsynergies.org/ wp-content/uploads/2018/02/IMB-NCDs-guideline.pdf

25 Amendezo E, Walker Timothy D, Karamuka V, et al. Effects of a lifestyle education program on glycemic control among patients with diabetes at Kigali university Hospital, Rwanda: a randomized controlled trial. Diabetes Res Clin Pract 2017;126:129-37.

26 Boyer JG, Earp JA. The development of an instrument for assessing the quality of life of people with diabetes. Diabetes-39. Med Care 1997;35:440-53.

27 Watkins K, Connell CM. Measurement of health-related QOL in diabetes mellitus. Pharmacoeconomics 2004;22:1109-26.

28 Beaton DE, Bombardier C, Guillemin F, et al. Guidelines for the process of cross-cultural adaptation of self-report measures. Spine 2000;25:3186-91.

29 Queiroz FAde, Pace AE, Santos CBdos. Cross-cultural adaptation and validation of the instrument Diabetes - 39 (D-39): brazilian version for type 2 diabetes mellitus patients - stage 1. Rev Lat Am Enfermagem 2009;17:708-15.

30 Nyanzi R, Wamala R, Atuhaire LK. Diabetes and quality of life: a Ugandan perspective. J Diabetes Res 2014;2014:1-9.

31 Fritz CO, Morris PE, Richler JJ. Effect size estimates: current use, calculations, and interpretation. J Exp Psychol Gen 2012;141:2-18.

32 Akoglu H. User's guide to correlation coefficients. Turk J Emerg Med 2018;18:91-3.

33 Schober P, Boer C, Schwarte LA. Correlation coefficients: appropriate use and interpretation. Anesth Analg 2018;126:1763-8.

34 Jing X, Chen J, Dong Y, et al. Related factors of quality of life of type 2 diabetes patients: a systematic review and meta-analysis. Health Qual Life Outcomes 2018;16:189.

35 Reba K, Argaw Z, Walle B, et al. Health-Related quality of life of patients with diagnosed type 2 diabetes in Felege Hiwot referral
Hospital, North West Ethiopia: a cross-sectional study. BMC Res Notes 2018;11:544.

36 Walker RJ, Lynch CP, Strom Williams J, et al. Meaning of illness and quality of life in patients with type 2 diabetes. $J$ Diabetes Complications 2015;29:665-9.

37 Choi YJ, Lee MS, An SY, et al. The relationship between diabetes mellitus and health-related quality of life in Korean adults: the fourth Korea National health and nutrition examination survey (2007-2009). Diabetes Metab J 2011;35:587-94.

38 Daya R, Bayat Z, Raal FJ. Effects of diabetes mellitus on healthrelated quality of life at a tertiary hospital in South Africa: a crosssectional study. S Afr Med J 2016;106:918-28.

39 Daher AM, AIMashoor SAH, Winn T. Glycaemic control and quality of life among ethnically diverse Malaysian diabetic patients. Qual Life Res 2015;24:951-8.

40 Robertson RP. Beta-Cell deterioration during diabetes: what's in the gun? Trends Endocrinol Metab 2009;20:388-93.

41 Saito I, Inami F, Ikebe T, et al. Impact of diabetes on health-related quality of life in a population study in Japan. Diabetes Res Clin Pract 2006;73:51-7.

42 Shim YT, Lee J, Toh MPHS, Toh M, et al. Health-Related quality of life and glycaemic control in patients with type 2 diabetes mellitus in Singapore. Diabet Med 2012;29:e241-8.

43 Camacho F, Anderson RT, Bell RA, et al. Investigating correlates of health related quality of life in a low-income sample of patients with diabetes. Qual Life Res 2002;11:783-96.

44 Tapela Net al. Diabetes in rural Rwanda: high retention and positive outcomes after 24 months of follow-up in the setting of chronic care integration. Int J Diabetes Clin Res 2016;3.

45 Camara A, Baldé NM, Sobngwi-Tambekou J, et al. Poor glycemic control in type 2 diabetes in the South of the Sahara: the issue of limited access to an HbA1c test. Diabetes Res Clin Pract 2015;108:187-92.

46 Solli O, Stavem K, Kristiansen IS. Health-Related quality of life in diabetes: the associations of complications with EQ-5D scores. Health Qual Life Outcomes 2010;8:18.

47 Mikailiūkštienè A, Juozulynas A, Narkauskaite L, et al. Quality of life in relation to social and disease factors in patients with type 2 diabetes in Lithuania. Med Sci Monit 2013;19:165-74.

48 Papadopoulos AA, Kontodimopoulos N, Frydas A, et al. Predictors of health-related quality of life in type II diabetic patients in Greece. BMC Public Health 2007;7:186.

49 Gatege R, Amendezo E, Twagirumukiza M. Clinical patterns and complications of African diabetic patients: preliminary data from Kigali university teaching Hospital, Rwanda. African J Diabetes Med 2012;20:39-42

50 Mbanya J, Ramiaya K. Diabetes mellitus. In: Jamison D, Feachem $\mathrm{R}$, Makgoba M, eds. Disease and mortality in sub-Saharan Africa. Washington (DC: The International Bank for Reconstruction and Development/The World Bank, 2006. https://www.ncbi.nlm.nih.gov/ books/NBK2291/

51 Lalkhen $\mathrm{H}$, Mash R. Multimorbidity in non-communicable diseases in South African primary healthcare. S Afr Med J 2015;105:134-8.

52 Chen G, lezzi A, McKie J, et al. Diabetes and quality of life: comparing results from utility instruments and Diabetes-39. Diabetes Res Clin Pract 2015;109:326-33.

53 Alfian SD, Sukandar H, Lestari K, et al. Medication adherence contributes to an improved quality of life in type 2 diabetes mellitus patients: a cross-sectional study. Diabetes Ther 2016;7:755-64.

54 Javanbakht M, Abolhasani F, Mashayekhi A, et al. Health related quality of life in patients with type 2 diabetes mellitus in Iran: a national survey. PLoS One 2012;7:e44526.

55 Gill GV, Mbanya J-C, Ramaiya KL, et al. A sub-Saharan African perspective of diabetes. Diabetologia 2009;52:8-16.

56 Mauvais-Jarvis F, Sobngwi E, Porcher R. Ketosis-Prone type 2 diabetes in patients of sub-Saharan African origin. Diabetes 2004;53:645-53.

57 Huang I-C, Hwang C-C, Wu M-Y, et al. Diabetes-specific or generic measures for health-related quality of life? Evidence from psychometric validation of the D-39 and SF-36. Value Health 2008;11:450-61. 